\title{
Hemoneumotórax espontáneo masivo idiopático en una mujer joven
}

\section{Spontaneous massive idiopathic haemopneumothorax in a young woman}

\author{
T. Belzunegui ${ }^{1}$, C. Jean Louis ${ }^{2}$, C. Beaumont ${ }^{2}$, J. Oteiza ${ }^{3}$
}

\section{SR. DIRECTOR:}

El hemoneumotoráx espontáneo (HNE) es definido como la acumulación de más de $400 \mathrm{ml}$ de sangre en la cavidad pleural en asociación con neumotórax. Es una entidad clínica rara y con una prevalencia estimada según diferentes estudios entre el 2 y el $12 \%$ de los neumotórax espontáneos ${ }^{1}$.

Clínicamente se suele manifestar más frecuentemente por los signos del neumotórax que los de la hemorragia aguda, y sólo un tercio de los mismos suele presentar un cuadro de shock hipovolémico ${ }^{1}$. Por ello, en ausencia de traumatismo, se convierte en un cuadro difícilmente sospechado.

Afecta fundamentalmente a hombres jóvenes. Precisa un diagnóstico precoz en el servicio de Urgencias y un tratamiento adecuado que incluye medidas de soporte vital con infusión de sangre si las pérdidas son importantes e intervención quirúrgica si el sangrado es continuo ${ }^{1}$.

Presentamos el caso de una mujer de 18 años que dos horas antes de su ingreso en su hospital de área sufrió un fuerte dolor en el costado derecho de intensidad creciente y que aumentaba con la inspiración profunda, motivo por el cual fue llevada al servicio de Urgencias.

La paciente no refería ninguna enfermedad ni hábito tabáquico. A su llegada al servicio de Urgencias, se encontraba consciente y orientada. La frecuencia cardiaca era de 148 latidos por minuto; la presión arterial de 108/70 mm Hg; la frecuencia respiratoria 20 respiraciones por minuto; la saturación arterial basal de oxígeno por pulsioximetría era del $100 \%$ y la temperatura de $37^{\circ} \mathrm{C}$. La glucemia fue de $140 \mathrm{mg} / \mathrm{dL}$.

La auscultación cardiaca mostraba una taquicardia rítmica sin soplos y la auscultación pulmonar un descenso del murmullo vesicular en la base derecha. No se evidenció ingurgitación yugular.

En la radiografía P-A de tórax (Fig. 1) se apreció un importante hidroneumotórax derecho con un colapso pulmonar total y
1. Servicio de Urgencias. Complejo Hospitalario de Navarra.

2. Servicio de Urgencias Rural.

3. Servicio de Medicina Interna. Complejo Hospitalario de Navarra.

Recepción: 23 de octubre de 2010

Aceptación provisional: 20 de enero de 2011

Aceptación definitiva: 25 de enero de 2011

\author{
Correspondencia \\ Tomás Belzunegui Otano \\ Servicio de Urgencias / Complejo Hospitalario \\ de Navarra \\ C/Irunalarrea 3 \\ 31008 Pamplona, Navarra. \\ Tel 34848422350 \\ E-mail: tomas.belzunegui.otano@cfnavarra.es
}


un nivel hidroaéreo que llegaba a campo medio pulmonar derecho. No se observa- ron imágenes patológicas sospechosas de otro proceso concomitante.

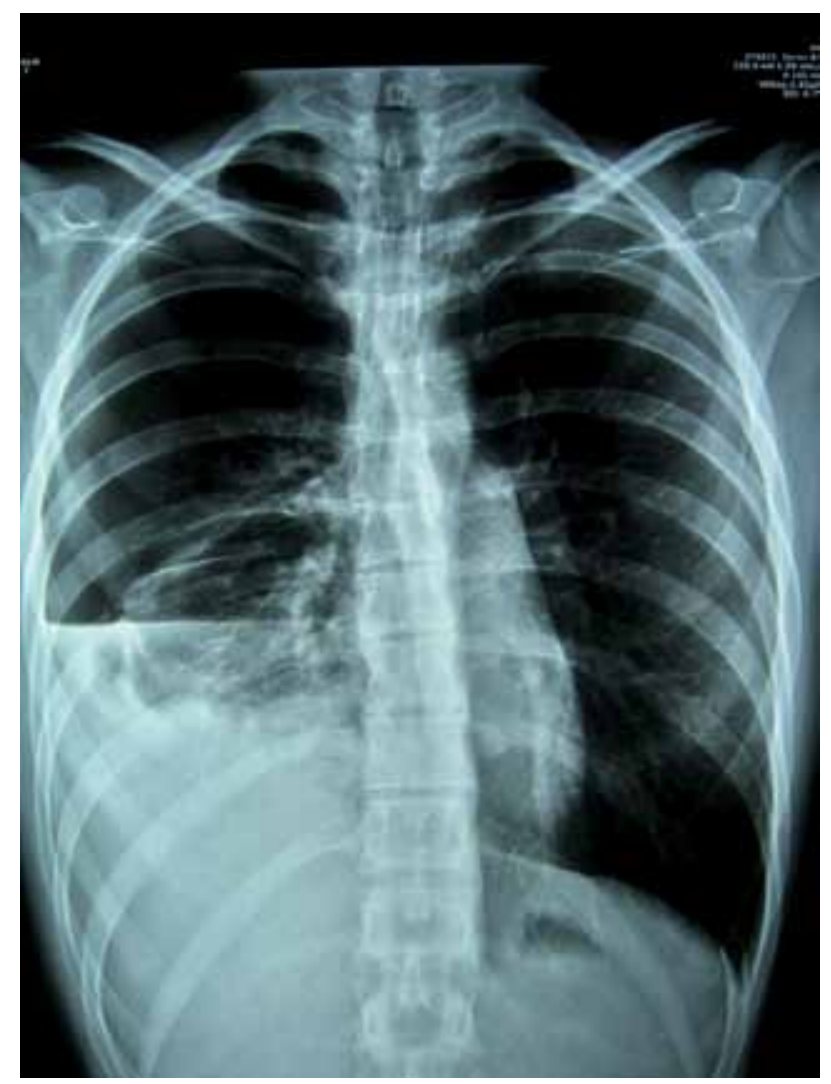

Figura 1.

Se realizó analítica de sangre que mostró una hemoglobina de $9 \mathrm{~g} / \mathrm{dL}, 10.500$ leucocitos $/ \mathrm{mm}^{3}$ y 208.000 plaquetas $/ \mathrm{mm}^{3}$. No se observaron alteraciones en los parámetros de coagulación ( $\mathrm{T}$ de protrombina: 12,5 segundos; Actividad de protrombina 98 \%; INR: 1,01; Tiempo de cefalina: 31,7 seg).

Al tratarse de un hospital primario sin servicio de cirugía torácica y de acuerdo con el hospital receptor (con servicio de cirugía torácica), se procedió al traslado de la paciente en ambulancia medicalizada con monitorización continua.

A su llegada al servicio de Urgencias, dada la situación de estabilidad hemodinámica de la paciente, bajo anestesia local se procedió a la inserción de un tubo torácico $\mathrm{n}^{\mathrm{o}} 18$ en el $5^{\mathrm{o}}$ espacio intercostal derecho, línea axilar anterior por el que se obtuvo en los primeros 10 minutos $1.200 \mathrm{ml}$ de sangre.

Tras la colocación del tubo, presentó un episodio de hipotensión arterial (80/35 $\mathrm{mm}$ de $\mathrm{Hg}$ ) que respondió a la administración de fluidos y a la perfusión de dos unidades de concentrado de hematíes. Se administró cobertura antibiótica con ceftriaxona ( $2 \mathrm{~g}$ intravenosos cada 24 horas durante 7 días).

Tras la primera aspiración drenaron otros $450 \mathrm{ml}$ de sangre en las siguientes 24 horas. Posteriormente no se objetivó sangrado y se retiró el tubo de tórax a los 7 días. 
El TC torácico realizado para detectar bullas u otra patología pleuropulmonar como causa del proceso no mostró alteraciones.

La evolución de la paciente fue favorable y no presentó complicaciones en los siguientes 12 meses.

El HNE masivo precisa un diagnóstico precoz para poder realizar el tratamiento adecuado. Dicho diagnóstico no es dificultoso ya que se realiza con una radiografía de tórax simple 2 .

Los casos descritos en la literatura que cursaron con hipovolemia sangraron entre 450 y $3.000 \mathrm{ml}$ con una media de $1.300 \mathrm{ml}$, lo que justificaría que dos tercios de los pacientes no presentaran cuadro de shock a su llegada a urgencias ${ }^{1}$.

Se han descrito diferentes procesos relacionados con el HNE como enfermedad reumática con afectación pulmonar, exostosis costal, ruptura de bullas pulmonares, discrasias sanguíneas, presencia de sangrado vascular por vasos aberrantes, aunque en ocasiones, no se ha llegado a determinar el origen del sangrado como este caso ${ }^{2-3}$.

Se han aconsejado diferentes estrategias terapéuticas por diferentes autores. Algunos consideran que todos los HNE deben ser tratados con toracoscopia ${ }^{4}$ mientras que otros demuestran que el tratamiento conservador es efectivo en una quinta parte de los pacientes ${ }^{2} \mathrm{y}$ por tanto aconsejan un tratamiento conservador con drenaje del hemotórax y vigilancia de la evolución del mismo por si es necesaria la intervención quirúrgica.

Desde el punto de vista terapéutico, la descompresión torácica en los HNE es controvertida ya que se ha objetivado que puede favorecer tanto la hemostasia de la pleura parietal como su sangrado ${ }^{5}$. Por este motivo y ante la estabilidad hemodinámica y respiratoria se optó por el traslado a un centro en el que de haber complicaciones relacionadas con el sangrado pleural pudiera realizarse una toracoscopia de urgencia.

Además, también se encuentra en controversia la aspiración simple tanto por su dudosa utilidad como por la existencia de complicaciones de sangrado, que podría llevar a equívocos en el diagnóstico etiológico ${ }^{6}$.

Estos casos se presentan fundamentalmente en varones en un $80-100 \%$ de las series $^{7,8}$ aunque ocasionalmente se han descrito casos de mujeres ${ }^{9}$.

En el manejo del paciente se optó por un tratamiento conservador con administración de oxigenoterapia, canalización de dos vías venosas para garantizar el aporte de volumen en caso de hipovolemia y el drenaje torácico del HNE. En su evolución se puso especial énfasis en la vigilancia de la paciente en una unidad de Observación de Urgencias, el control de la velocidad de sangrado por el tubo de drenaje torácico y la valoración de la necesidad de tratamiento quirúrgico. Se estableció contacto con el servicio de Cirugía Torácica para una eventual toracoscopia en caso de deterioro hemodinámico.

Esta experiencia muestra que es posible el tratamiento conservador con punción en casos de HNE siempre que se cuente con los medios necesarios para una vigilancia del sangrado torácico y un servicio de Cirugía Torácica para solucionar el mismo.

En hospitales de primer nivel donde no exista servicio de Cirugía Torácica no se debe drenar el hemotórax si la situación es estable ya que en ocasiones se ha descrito empeoramiento del cuadro por este motivo ${ }^{5}$. La estrategia más adecuada desde nuestro punto de vista es el traslado urgente en ambulancia medicalizada del paciente a un hospital que cuente con dicho servicio, para la realización del drenaje torácico.

\section{BIBLIOGRAFÍA}

1. Kim ES, Kang JY, Pyo CH, Jeon EY, LeE WB. 12-year experience of spontaneous hemopneumothorax. Ann Thorac Cardiovasc Surg 2008; 14: 149-153.

2. KaKaris S, Athanassiadi K, Vassilikos K, Skottis I. Spontaneous hemopneumothorax: A rare but life-threatening entity. Eur J Cardiothorac Surg 2004; 25: 856-858. 
3. Basoglu A, Celik B, Yetim TD. Massive spontaneous hemopneumothorax complicating rheumatoid lung disease Ann Thorac Surg 2007; 83: 1521-1523.

4. Homma T, Sugiyama S, КотоH K, DoKi Y, Tsuda M, MISAKI T. Early surgery for treatment of spontaneous hemopneumothorax. Scand J Surg 2009; 98: 160-163.

5. Por NC, FaI CL, Hung CC. Spontaneous massive haemopneumothorax: Case reports. Eur J Emerg Med 2003; 10: 47-51.

6. Hamaguchi $\mathrm{N}$, Tamaki M, IchiKawa $\mathrm{Y}$, Toba $\mathrm{H}$, Oonishi K, FuJISHIma $\mathrm{N}$ et al. Three cases of emergency video-assisted thoracoscopic surgery for spontaneous hemopneumothorax. Kyobu Geka 2001; 54: 995-998.

7. Hentel K, Brill PW, Winchester P. Spontaneous hemopneumothorax. Pediatr Radiol 2002; 32: 457-459.

8. Medina JC, Diaz-Guijarro J, Castejón R. Hemoneumotórax espontáneo. Emergencias 2008; 20: 367-368.

9. Tanaka F, Esaki H, Isobe J, Ueno Y, Inoue R, Ito $M$ et al. Four cases of spontaneous hemopneumothorax. Kyobu Geka 1990; 43: 10561059 . 